\title{
CONCENTRAÇÃO DE CRÔMIO EM ÁGUA E SEDIMENTO EM ÁREA DE DESCARTE DE RESÍDUOS DE CURTUME
}

\author{
Beatris Cordeiro Gonçalves, Daniel Ângelo Macena, Vinícius Marques Gomes \\ Universidade do Oeste Paulista, Curso de Química Bacharelado, Presidente Prudente, SP. E-mail: \\ danielangelo@live.com.
}

\begin{abstract}
RESUMO
Um setor que está gerando grandes quantidades de resíduos tóxicos são as indústrias de couro por utilizarem o Crômio no processo de tratamento para dar estabilidade ao couro. O Crômio no seu estado de oxidação trivalente é estável no solo e essencial para o homem. Já o Crômio hexavalente é prejudicial ao solo e para o homem pode acarretar varias doenças por ser potencialmente mutagênico e cancerígeno. Este estudo teve como objetivo avaliar o teor de Crômio total no sedimento e água do Córrego do Veado, em Presidente Prudente- SP por técnica de espectrometria de absorção atômica em chama. Os resultados das amostras de água e sedimentos apresentaram-se acima do valor máximo permitido pela legislação vigente ou em estado de alerta. Conclui-se que apesar de a própria empresa fazer o tratamento antes da destinação final, ainda assim, o resíduo está inadequado para descarte direto em qualquer corpo hídrico.

Palavras-chave: Indústria de Couro; Compartimentos ambientais; Crômio; Contaminação.
\end{abstract}

\section{CONCENTRATION OF CHROMIUM IN WATER AND SEDIMENT IN THE AREA OF FINAL DISPOSAL OF WASTE OF TANNERY}

\begin{abstract}
An industry that is generating large amounts of toxic waste is the leather industry because it uses chromium in the treatment process to give leather stability. Chromium in its trivalent oxidation state is stable in soil and essential for man. Hexavalent chromium is harmful to the soil and can lead man to various diseases because it is potentially mutagenic and carcinogenic. The objective of this study was to evaluate the total Chromium content in the sediment and the water of Córrego do Veado, in Presidente Prudente-SP, using the atomic absorption spectrometry technique. The results of the water and sediment samples presented above the maximum permitted value of the legislation in force or in a state of alert. It is concluded that although the company possesses the treatment before the final destination, still, there are residues available, by the way, should not eliminate in any body of water.
\end{abstract}

Keywords: Leather industry, Environmental compartiments; Chromium; Contamination. 


\section{INTRODUÇÃO}

O rápido desenvolvimento industrial pode, por muitas vezes, aumentar os impactos ambientais que seriam minimizados se todos os resíduos gerados tivessem um destino final adequado. Porém não é incomum o descarte inadequado de resíduos gerados pelas indústrias, tornando cada vez maior o problema quanto à poluição e a não preservação dos ecossistemas, tornando uma ameaça para a saúde do homem, plantas e animais (KRAEMER, 2014).

O Brasil produz mais de 30 milhões de toneladas de resíduos industriais, do qual, 25 milhões de toneladas do resíduo produzido não recebem o tratamento adequado antes do destino final. Esta irregularidade acarreta uma perda em torno de $\mathrm{R} \$ 600$ milhões/ano aos cofres municipais. Da quantidade que é descartada de forma irregular, seria necessário um investimento de mais de $R \$ 3$ bilhões para adequar o que ainda é destinado de forma irregular (ABETRE, 2016).

Esses resíduos, descartados sem tratamento adequado, podem depositar-se facilmente de forma antrópica nos solos e na água, alterando suas propriedades físicas e químicas (FELISBERTO et al., 2008). A maioria desses resíduos contém metais potencialmente tóxicos, sendo alguns deles o Cádmio, Crômio, Manganês e Níquel e são altos contaminantes de lençóis freáticos, rios, lagos e reservatórios, que são captados para abastecimento da população. Esses contaminantes podem causar sérios problemas de saúde, tais como, câncer, cefaleia, desmaios, náuseas e irritações neuromusculares (JIMENEZ; DAL BOSCO; CARVALHO, 2004).

Dentre os metais de maior uso no setor industrial está o Crômio, presente na fabricação de aço inoxidável, pigmentos, cerâmica, borracha, fitas magnéticas e em curtumes. No processamento do couro a etapa de curtimento é fundamental e consiste na reação de espécies químicas, como o Crômio interagindo proteínas, ocorrendo a transformação do colágeno da pele em couro pelo entrelaçamento das protofibrilas do colágeno. O couro obtido pelo curtimento com Crômio caracteriza-se por elevada estabilidade hidrotérmica, maior flexibilidade e resistência que são características desejadas pelo mercado consumidor (SANTOS et al., 2009).

O Crômio foi descoberto por Nicolas-Louis Vauquelin em 1797 na Sibéria, na forma de Cromato de Chumbo $\left(\mathrm{PbCrO}_{4}\right)$. O Crômio foi isolado em 1798 , reduzido a Cromato $\left(\mathrm{CrO}_{3}{ }^{-}\right)$com carvão mineral, em altas temperaturas. Sugeriu-se o nome Crômio (do grego, Cromo= Cor) devido à cor intensa de seus compostos. É um metal branco, lustroso, duro e quebradiço, de densidade $7,19 \mathrm{~g} .\left(\mathrm{cm}^{3}\right)^{-1}$ e ponto de fusão de $1930 \pm 10$ C, que se apresenta com estrutura cúbica de corpo centrado. Em temperaturas elevadas este elemento pode se ligar diretamente aos Halogênios, Enxofre, Silício, Boro, Nitrogênio, Carbono e Oxigênio (OUELHADJ, 2007).

O Crômio pode ser encontrado em diversos estados de oxidação, $\mathrm{Cr}(\mathrm{II}), \mathrm{Cr}(\mathrm{III}), \mathrm{Cr}(\mathrm{IV}), \mathrm{Cr}(\mathrm{V})$ e $\mathrm{Cr}(\mathrm{VI})$. Os mais estáveis são o $\mathrm{Cr}(\mathrm{III})$, trivalente, essencial à nutrição humana e quando ausente na dieta, causa a diabetes e problemas cardiovasculares, e o $\mathrm{Cr}(\mathrm{VI})$ hexavalente, é classificado como potencialmente tóxico por ser altamente oxidante, causando problemas ao organismo, pois atravessam as membranas biológicas e por sua vez, considerado carcinógeno e mutagênico ( SANTOS et al., 2009).

Segundo Gonçalves et al. (2011), tanto por emenda do lodo de curtume como de forma natural o Crômio pode estar presente de forma indesejada. Logo, essas são as condições na qual o Crômio pode estar presente na cadeia alimentar e em altas concentrações causam sérios problemas de intoxicação, além da diminuição no rendimento das plantas e também doenças nos seres humanos e/ou animais.

Segundo a Resolução 357 do Conama, de 17 de Março de 2005, que estabelece o valor máximo permitido (VMP) de Crômio nos corpos hídricos, onde os rios de classe I (águas doces), são permitidos até $0,05 \mathrm{mg} \cdot \mathrm{L}^{-1} \mathrm{Cr}$ e classe II (águas salinas), são permitidos até $1,10 \mathrm{mg} \cdot \mathrm{L}^{-1} \mathrm{Cr}$.

De acordo com a Resolução do CONAMA 344, de 25 de março de 2004 é regulamentado o VMP de Crômio em sedimentos, onde a classificação segue como nível 1 (que não se observa 
efeito adverso à biota) e nível 2 (valor acima do qual se observa efeito adverso à biota. Sendo o VMP 37,3 e 90,0 mg. $\mathrm{kg}^{-1} \mathrm{Cr}$, respectivamente.

Portanto, este trabalho teve como objetivo determinar a concentração de Crômio em água e sedimento, proveniente do processamento de couros em curtume de Presidente Prudente- SP, por espectrometria de absorção atômica em chamas (FAAS).

\section{METODOLOGIA}

As amostras de sedimento e água foram coletadas no Córrego do Veado de Presidente Prudente-SP e avaliadas no laboratório de análises físicas e químicas de solos da Universidade do Oeste Paulista - UNOESTE.

Antes de toda e qualquer análise, foi realizado o preparo das vidrarias, principalmente em se tratando de análise de metais é de grande importância que seja previamente limpa de forma adequada. A limpeza de toda a vidraria utilizada foi executada com vapor de ácido nítrico num sistema de refluxo concentrado segundo método proposto por TSCHOPEL et al. (1980) e GOMES (2010).

As amostras de sedimentos após a coleta foi transferida para placas de Petri e secas em estufa a $120^{\circ} \mathrm{C}$, seguidamente passadas pelo processo de desagregação e peneiramento $(2 \mathrm{~mm}$ ).

A técnica analítica utilizada para a determinação do teor de Crômio total nas amostras de água e sedimentos foi espectrometria de absorção atômica em chamas (FAAS), marca Perkin Elmer - modelo AAnalyst, uma técnica utilizada em laboratórios para ensaios químicos de larga escala (CADORE; MATOSO \& SANTOS, 2008)..

A Figura 1 representa a demarcação de como se procedeu à coleta das amostras, num total de seis pontos tanto para a coleta de água quanto a de sedimento. O mapa foi adquirido por meio de imagem orbital retirado do Google Earth ${ }^{\circledR}$.

Figura 1. Mapa da demarcação dos pontos de coleta de amostras.

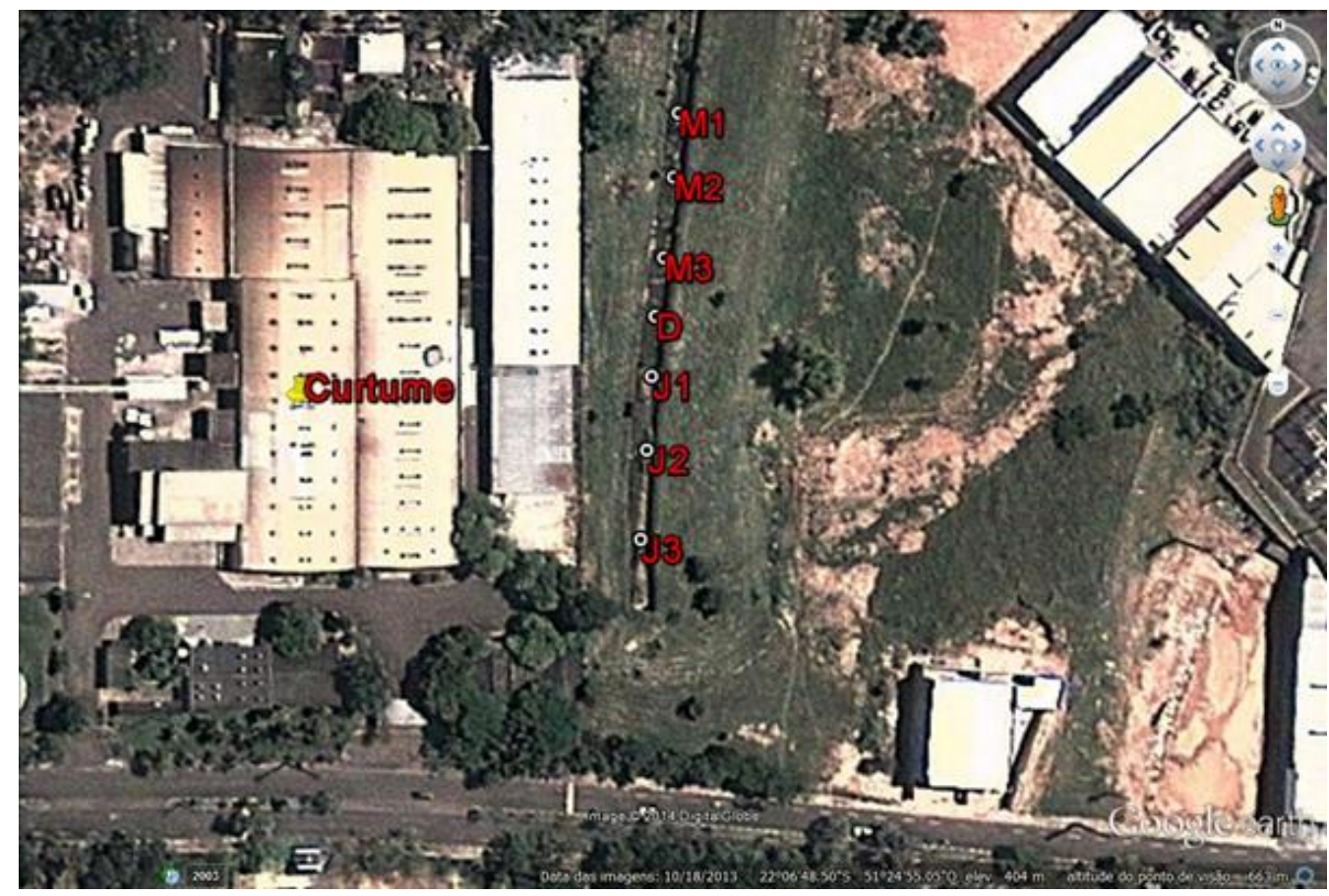

Fonte: Próprio autor

Nota: $M=$ Montante: direção de um ponto mais baixo para o mais alto; J= Jusante: fluxo normal da água, de um ponto mais alto para um ponto mais baixo. $D=$ Descarte: Onde o curtume descarta o resíduo tratado. 
As amostras de sedimentos foram coletadas e transferidas para placas de Petri, seguidamente foram secas em estufa a $120^{\circ} \mathrm{C}$ e passadas pelo processo de desagregação e peneiramento a $2 \mathrm{~mm}$.

Foi transferido aproximadamente $2,0 \mathrm{~g}$ de amostra para tubo de digestão e acondicionado em bloco digestor. Adicionou-se $10 \mathrm{~mL}$ de solução de Ácido Nítrico concentrado e seguiu aquecimento a 120 ㄷ. Em seguida, foi adicionado $1 \mathrm{~mL}$ de solução de Peróxido de Hidrogênio $30 \%$ $(\mathrm{v} / \mathrm{v})$ e permaneceu no bloco digestor até a digestão completa por um tempo total de digestão de 2 horas. O extrato pós-digestão foi transferido para um balão volumétrico de $100 \mathrm{~mL}$ e completado até o menisco com água destilada. E então foram submetidas à leitura no FAAS em triplicata.

Para a digestão da água foi utilizado tubos digestores fazendo uso do mesmo bloco digestor, em mesma temperatura que foi executada o processo de digestão das amostras de sedimento, porém no tubo dispôs-se de $100 \mathrm{~mL}$ da amostra, seguido de $10 \mathrm{~mL}$ de Ácido Nítrico concentrado. Seguiu-se o processo de evaporação até que subsistisse $50 \mathrm{~mL}$ de amostra. Em seguida, foi adicionado também $1 \mathrm{~mL}$ de solução de Peróxido de Hidrogênio $30 \%(\mathrm{v} / \mathrm{v})$ sob aquecimento até o fim da digestão ( 2 horas). Como no processo do sedimento, o extrato pósdigestão foi transferido para um balão volumétrico de $100 \mathrm{~mL}$ e completado até o menisco com água destilada. Em seguida, submetidas à leitura no FAAS em triplicata.

\section{RESULTADOS}

Antes de realizar as análises das amostras de água montante e jusante foi realizada também análise do efluente bruto e do efluente tratado (Tabela 1), para uma melhor comparação no resultado final da concentração de Crômio disponível no corpo hídrico em estudo e analisar a eficiência da estação de tratamento de efluente do curtume em estudo. De acordo com a Tabela 1 , foram utilizadas as médias das amostras, montante e jusante, devido o córrego apresentar um curto espaço entre um ponto e outro e então ser comparados com a Resolução 357/05 do CONAMA.

Tabela 1. Média dos resultados das análises da água do córrego e efluentes bruto e tratado.

\begin{tabular}{|c|c|c|c|c|c|}
\hline \multicolumn{5}{|c|}{ Águas } \\
\hline $\begin{array}{c}\text { Resolução 357/05 do CONAMA } \\
\text { (VMP) }\end{array}$ & EB & ET & $\mathbf{M}_{\mathbf{M}}$ & $\mathbf{M}_{\mathbf{J}}$ \\
\hline Rios Classe I & $0,05 \mathrm{mg} \mathrm{L}^{-1} \mathrm{Cr}$ & & & & \\
\hline Rios Classe II & $1,10 \mathrm{mg} \mathrm{L}^{-1} \mathrm{Cr}$ & $58,59 \mathrm{mg} \mathrm{L}^{-1} \mathrm{Cr}$ & $5,58 \mathrm{mg} \mathrm{L}^{-1} \mathrm{Cr}$ & $1,62 \mathrm{mg} \mathrm{L}^{-1} \mathrm{Cr}$ & $6,61 \mathrm{mg} \mathrm{L}^{-1} \mathrm{Cr}$ \\
\hline DP & 0,02 & 0,02 & 0,09 & 0,10 \\
\hline
\end{tabular}

Fonte: Dados experimentais

Nota: $\mathrm{VMP}=$ Valor Máximo Permitido; $\mathrm{EB}=$ Efluente Bruto; $\mathrm{ET}=$ Efluente Tratado; $\mathrm{M}_{\mathrm{M}}=$ Média das amostras "Montante"; $M_{\mathbf{J}}=$ Média das amostras "Jusante"; DP= Desvio Padrão, Cr= Crômio.

Após as análises dos sedimentos foram calculadas as médias para montante e jusante e depois comparadas com a Resolução 344/04 do CONAMA. 
Tabela 2. Média dos resultados das análises do sedimento

\begin{tabular}{|c|c|c|c|}
\hline \multicolumn{4}{|c|}{ Sedimentos } \\
\hline \multicolumn{2}{|c|}{$\begin{array}{l}\text { CONAMA } \\
(\mathrm{VMP})^{*}\end{array}$} & $M_{M}$ & $\mathbf{M}_{\mathbf{J}}$ \\
\hline Nível 1 & $37,3 \mathrm{mg} \mathrm{Kg}^{-1} \mathrm{Cr}$ & \multirow{2}{*}{$3,22 \mathrm{mg} \mathrm{Kg}^{-1} \mathrm{Cr}$} & \multirow{2}{*}{$72,17 \mathrm{mg} \mathrm{Kg}^{-1} \mathrm{Cr}$} \\
\hline Nível 2 & $90,0 \mathrm{mg} \mathrm{Kg}^{-1} \mathrm{Cr}$ & & \\
\hline \multicolumn{2}{|c|}{ DP } & 0,02 & 0,34 \\
\hline
\end{tabular}

Fonte: Dados experimentais

Nota: $\mathrm{VMP}=$ Valor Máximo Permitido; $\mathrm{M}_{\mathrm{M}}=$ Média das amostras "Montante"; $\mathrm{M}_{\mathrm{J}}=$ Média das amostras "Jusante"; DP= Desvio Padrão; $\mathrm{Cr}=$ Crômio.

\section{DISCUSSÃO}

Segundo os resultados das análises do EB e ET apresentados na Tabela 1 percebe-se que a estação de tratamento de efluente da empresa apresenta uma eficiência de mais de $90 \%$ na remoção do Crômio disponível, porém o ET apresentou um resultado até 100 vezes maior que o VMP, comparando com o valor para rios de classe I da Resolução do CONAMA 357/05, ao qual é a classificação que o Córrego do Veado recebe.

Comparando as médias das análises realizadas da água do córrego, pôde-se observar que os pontos coletados no montante obteve uma concentração disponível de Crômio, aproximadamente, 22 vezes menor do que os pontos coletados da jusante, porém apresentaramse muito acima do VMP que a Resolução 357/05 regulamenta. Um dos grandes problemas encontrados na atualidade é a poluição ambiental, ao comparar o resultado da água do córrego jusante, 6,61 mg. $\mathrm{L}^{-1}$, com o resultado do $\mathrm{ET}, 5,58 \mathrm{mg} \mathrm{L}^{-1}$, pode-se dizer que no corpo hídrico apresenta uma concentração maior de Crômio porque além de ser um íon mutagênico, carcinogênico e oferecer grandes riscos à fauna e flora local, o Crômio também é considerado acumulativo ambiental (PIRETE et al., 2009).

Ao observar a Tabela 2, análises do sedimento, percebe-se que o resultado para o sedimento coletado na montante está abaixo do nível 1 , e o sedimento coletado na jusante apresentou um resultado entre o nível 1 e 2. De acordo com a Resolução 344/04 do CONAMA, no Art. 70 diz que se o material cuja concentração do metal estiver entre os níveis 1 e 2, deve ser submetido a ensaios ecotoxicológicos, entre outros testes que venham a ser exigidos pelo órgão ambiental competente ou propostos pelo empreendedor, de modo a enquadrá-lo nos critérios previstos nos incisos I e II do Art. 7ㅇ.

\section{CONCLUSÃO}

Os riscos de descarte indiscriminado de resíduos contendo metais potencialmente tóxicos aos compartimentos ambientais estão associados principalmente ao transporte e destinação desses poluentes no ambiente. $O$ descarte indiscriminado de resíduos deve ser evitado, visto que o Crômio ainda é muito utilizado nos processos industriais e é considerado um íon acumulativo tanto em água como em sedimentos.

Neste trabalho pôde-se perceber que devido a processos industriais ocorre contaminação das águas superficiais e dos sedimentos do Córrego do Veado situado em Presidente Prudente-SP, uma vez que todos os resultados obtidos estão acima do valor máximo permitido pela legislação ou em estado de alerta, que é o caso dos sedimentos.

Portanto, sugere-se que seja realizado um monitoramento ambiental da área de estudo e/ou ensaios ecotóxicologicos como orienta a legislação em resultados de alerta. 


\section{REFERÊNCIAS}

ABETRE - ASSOCIAÇÃO BRASILEIRA DE EMPRESAS DE TRATAMENTO DE RESÍDUOS. Destinação irregular de resíduos. São Paulo: ABETRE, 2016.

CADORE, S.; MATOSO, E.; SANTOS, M. C. A espectrometria atômica e a determinação de elementos metálicos em material polimérico. Quím. Nova, São Paulo, v. 31, n. 6, p. 15331542,2008. https://doi.org/10.1590/S0100-40422008000600044.

FELISBERTO, R., VIEIRA, L. O., COUTO, A., SCHUH, R., ALBINO, C. T., LIBARDI, D. B. e da CUNHA, A. C. B. De resíduo a insumo: a construção do caminho para uma química mais limpa através de um projeto de ensino. Quím. Nova, v. 31, n. 1, São Paulo, 2008.

GOMES, V. M. Estudo da mobilidade do crômio em área de descarte inadequado de resíduos de couro: possível contaminação de solos, águas e sedimentos. 2010. 83 f. Dissertação (mestrado) Universidade Estadual Paulista, Instituto de Química, 2010. Disponível em: <http://hdl.handle.net/11449/97798>.

GONÇALVES, A. C.; NACKE, H.; SCHWANTES, D.; NAVA, I. A.; STREY, L. Phytoavailability of toxic heavy metals and productivity in wheat cultivated under residual effect of fertilization in soybean culture. Water, Air, \& Soil Pollution, v. 220, n. 1-4, p. 205-211, 2011, https://doi.org/10.1007/s11270-011-0747-3.

JIMENEZ, R. S.; DAL BOSCO, S. M.; CARVALHO, W. A. Remoção de metais pesados de efluentes aquosos pela zeólita natural escolecita-influência da temperatura e do pH na adsorção em sistemas monoelementares. Química Nova, v. 27, n. 5, p. 734-738, 2004, https://doi.org/10.1590/S0100-40422004000500011.

KRAEMER, Maria Elisabeth Pereira. A questão ambiental e os resíduos industriais. Acedido em, v. 15, 2014.

OUELHADJ, Akli. Identification and characterization of heavy metal induced genes in barley leaves (Hordeum vulgare L.). 2007. Tese de Doutorado.

PIRETE, M. M., DALCIN, M. G., CARDOSO, V. L., \& RESENDE, M. M. RESULTADOS PRELIMINARES DA REDUÇÃO BIOLÓGICA DE CROMO HEXAVALENTE EM FILTRO BIOLÓGICO DE FLUXO CONTÍNUO. XIII Congresso Brasileiro de Engenharia Química em Iniciação Científica. Universidade Federal de Uberlândia. 2009. Uberlândia - MG, Brasil.

RESOLUÇÃO, №. 357, de 17 de Março de 2005. CONAMA-Conselho Nacional de Meio Ambiente, 2005.

RESOLUÇÃO, №. 344, de 25 de março de 2004. CONAMA-Conselho Nacional de Meio Ambiente, 2004.

SANTOS, A. D.; OLIVEIRA, L. C. D.; BOTERO, W. G.; MENDONÇA, A. G. R.; SANTOS, F. A. D.; ROCHA, J. C. e OLIVEIRA, A. S. D. Distribuição e biodisponibilidade de crômio em solos contaminados por resíduos de couro. Química Nova, v. 32, n. 7, p. 1693-1697, 2009, https://doi.org/10.1590/S0100$\underline{40422009000700002 .}$. 
TSCHÖPEL, P.; KOTZ, L.; SHULZ, W.; VEBER, M.; TÖLG, G. Zur Ursache und Vermeidung systematischer fehler bei elementbestimmungen in wäßrigen lösungenim $\mathrm{ng} / \mathrm{ml}-$ und $\mathrm{pg} / \mathrm{ml}$. Fresenius J. Anal. Chem., v. 302, n. 3, p. 1-14, 1980. 